\title{
Guidelines on the Management of Atlanto-Axial Fractures in Adults: A Short Review
}

\author{
Vibhu Krishnan Viswanathan* and Surabhi Subramanian \\ Clinical Spine Fellow, USA \\ *Corresponding author: Vibhu Krishnan Viswanathan, Clinical Spine Fellow, Columbus, Ohio - 43202, USA

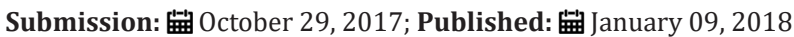

\begin{abstract}
Fractures of upper cervical spine are very rare. The principles underlying the management of injuries to atlas and axis in adult patients are different from sub-axial spine. The current article comprehensively outlines the rationale behind the management of these injuries and discusses the guidelines based on the existing literature. A majority of these fractures can be managed conservatively. Specific indications for rigid immobilization and surgical fusion have been outlined in this article.
\end{abstract}

\section{Fractures of Atlas}

Acute atlas (C1) fractures are rare injuries, accounting for 2-13\% of all cervical spine fractures [1]. Although previously described by Cooper et al in 1822, the report by Jefferson et al. in 1920 was of the greatest historic significance [2]. The greatest emphasis, as far as the management of this injury is concerned, has largely been placed on the intactness of transverse atlantal ligament (TAL) [3].

The identification of injury to this ligament has traditionally been on the basis of open-mouth radiographs [3]. However, MRI has a much greater sensitivity in identifying any underlying damage of transverse atlantal ligament [4]. The traditional diagnosis of violation of TAL was described as the Spence rule $6.9 \mathrm{~mm}$ displacement of C1 lateral mass over C2. In 1993, Heller et al. [5] purported that $8.1 \mathrm{~mm}$ could be a better cut-off for identifying TAL rupture. In 1996, Dickman et al. [4] reported that in as many as $60 \%$ of patients with a negative Spence rule, an underlying TAL ligament injury could be discovered on the basis of an abnormal hyper-intense signal visualized on MR Imaging. They recommended a treatment protocol for atlas fracture on the basis of MR findings. Hein et al. [6] re-defined unstable atlas burst fractures or Jefferson fractures as fractures of anterior and posterior atlantal arches with rupture of TAL and incongruent atlanto-occipital and atlanto-axial joints.

Hadley et al. [5] proposed a treatment protocol for C1 fractures, on the basis of plain radiograph findings. They recommended initial management of $\mathrm{C} 1$ fractures with external immobilisation only (a majority of these fractures heal at around 12 weeks). Atlas fractures with combined lateral mass displacement (CLMD) of $6.9 \mathrm{~mm}$ or less were successfully managed with cervical collar. For a CMLD greater than $6.9 \mathrm{~mm}$, a more rigid immobilization with halo-orthosis or sub-occipital mandibular immobilizer was recommended. A similar line of management was proposed by
Fowler et al. [7]; and Levine \& Edward [8]. Late instability of such conservatively-managed C1fractures, although infrequent, can occur. Therefore, careful clinical and radiological follow-up is of utmost relevance until radiological union occurs [9]. Horn et al. [10] reviewed the complications following halo-fixation in elderly patients ( $>70$ years) and reported that halo immobilization was a safe procedure in these patients. Nevertheless, he cautioned about the higher incidence of complication rates associated with halovest immobilization in this population, as compared to younger patients (respiratory distress-9.5\%, dysphagia-14.3\% and pinrelated complications $-23.8 \%$ ).

In the post-MRI era, Lee et al. [11] classified the atlas fractures into three types: anterior or posterior arch fractures (Type 1), burst fractures (Type 2) and lateral mass fractures (Type 3). Type 1 and 3 fractures were considered stable and treated with rigid collar immobilisation. Type 2 fractures were further classified on the basis of associated TAL injury (diagnosed on LCMD $>7 \mathrm{~mm}$ or pre-dental interval $>5 \mathrm{~mm}$ or TAL rupture on MR Imaging). C1-2 fusion has been reported as treatment in such unstable pattern of type 2 injury. Another important consideration that should be kept in mind, before planning the management of TAL injuries is the actual location of ligament failure. Fractures with intra-substance rupture of TAL (Type 1 injury) are highly unstable and need to be considered for early surgical treatment. A TAL failure with a bony avulsion is relatively more stable and can potentially be managed with external immobilization [4].

\section{Fractures of Axis}

\section{Odontoid fractures}

Anderson \& Alonzo [12] classified odontoid fractures into three types: type 1 involving avulsion fracture of tip of odontoid, 
type 2 across the base of dens near the junction with body; and type 3 involving the body of axis. Grauer et al. [13] further subclassified type 2 fractures into: $2 \mathrm{~A}$-involving minimal or no displacement or comminution, $2 \mathrm{~B}$-involving displaced fracture extending antero-superior to postero-inferiorly or transverse fracture, amenable to anterior screw fixation; and 2C - extending from antero-inferior to posterior-superior direction or fracture with significant comminution, which are amenable to posterior fusion. Type $2 \mathrm{C}$ fractures respond less satisfactorily to conservative modalities of treatment [13]. Overall evidence suggests that the intial, recommended management in type 1, most of type 2 and type 3 fractures is external immobilization $[14,15]$. There is a current recommendation for early surgical stabilisation and fusion for type fractures in patients older than 50 years [14-16]. Surgical stabilisation and fusion of types 2 and 3 odontoid fractures is recommended when the displacement is more than $5 \mathrm{~mm}$, fracture is comminuted or it is difficult to maintain reduction with an external immobilization modality [16].

The options for conservative management include cervical traction (union rates reported in the literature of around 100\% in type $1,43 \%$ in type 2 and $87 \%$ in type 3 fractures), cervical collar (100\% union rates in type $1,53-57 \%$ in type 2 and $50-65 \%$ in type 3 fractures) and halo-immobilization, including custom devices including suboccipitomandibular brace and Minerva devices $(100 \%$ union rates for type 1, 72\% for type 2 and 99\% for type 3 fracture) $[16,17]$. The operative options for odontoid type 2 fractures include anterior screw fixation and posterior C1-2 fusion. Posterior C1-2 fusion is the modality of choice in type $2 \mathrm{C}$ injuries, old injuries not amenable to reduction and elderly patients especially with poor bone stock [17]. In the elderly patients with odontoid fractures, the ability to tolerate halo-immobilization is highly questionable; and mortality rates as high as $26 \%$ have been reported [16,18]. Frangen et al. [18] recommended early surgical intervention, in the form of posterior C1-2 fusion for the elderly patients.

\section{Hangman fracture}

The well-accepted classification scheme for traumatic spondylolisthesis of the axis was proposed by Effendi et al. [19], which included three types: type 1: isolated harline fracture (less than $3 \mathrm{~mm}$ displacement) of the ring of axis with minimal displacement (more than $3 \mathrm{~mm}$ displacement) of $\mathrm{C} 2$ body (axial loading+hyperextension injury), type 2: fractures of ring of axis wit displacement and C2-3 disc space disruption (hyperextension+rebound flexion); and type 3: fractures of ring of axis with displacement, flexed angulation and C2-3 facet dislocation of axis vertebra (flexion + rebound extension). Levine \& Edward [20] modified the Effendi classification system and proposed flexion distraction as another mechanism of injury. Type 2 was thus described as $>3 \mathrm{~mm}$ displacement and significant angulation of the anterior fragment, while 2A was described as severe angulation with minimal $(<3 \mathrm{~mm})$ displacement (flexion-distraction).

The initial management of most types of Hangman fractures is typically non-surgical, with high success rates [21]. The major factor to be considered in decision making is possibly the instability at
C2-3 level. Based on the systematic review by Li et al. [21] non-rigid external immobilization may be sufficient in most Levine Edwards type 1 and 2 injuries, traction followed by external immobilization may be used in Levine Edwards type 2 fractures, while more rigid immobilization or surgical fusion should be considered for Levine Edwards types $2 \mathrm{~A}$ and 3 injuries. It has also been reported that haloimmobilization does not always achieve or maintain immobilization, and there is an occasional need for surgical fusion in this sub-group of patients [22,23]. Multiple complications are also known to occur with halo-immobilization including pin loosening, infection, cranial fractures, poor compliance, chest infections, complications secondary to long time patient immobilization like pressure sores and deep venous thrombosis [21,23].

\section{Axis Body Fractures}

These are exceedingly rare fractures [24]. Benzel et al. [24] classified C2 body fractures into three types: type 1: coronal, type 2: sagittal and type 3: transverse fractures. Most of these fractures are managed conservatively [25]. In the study by Greene et al. [14], [25], 99\% of axis body fractures were treated conservatively with external immobilization. Many of these fractures extend into the transverse foramen and are associated with vertebral artery injuries [26]. Korres et al. [27] described a multiple atlas fracture pattern in $1 \%$ of patients. All patients with C2 fracture therefore need CT scan evaluation.

\section{Combination fractures of atlas and axis}

Owing to the unique bony anatomy of atlas and axis, combination fractures of these bones is not uncommon [28]. In the legendary study by Geoffrey et al. [29], 19 of the total 46 atlas fractures were actually combination fractures of these two bones. The incidence of concomitant injuries to $\mathrm{C} 1$ and odontoid process ranges from 5-53\%, while incidence of combination atlas and Hangman fractures ranges from 6 to $26 \%$ [30]. The usual combination injuries reported in the literature include combined bi-pedicular fracture of $\mathrm{C} 2$ with odontoid fracture, C1 posterior arch fracture with odontoid fracture, Jefferson fracture with odontoid fracture and C2 articular pillar fracture with odontoid fracture [30]. The incidence of neurological injury is also reported to be higher in combination injuries, as compared with isolated atlas or axis fractures [31].

Levine \& Edward [32] suggested that these combination fractures are best managed sequentially, allowing the atlas (in most situations) to heal first followed by attempting to definitively manage C2 injury. The treatment of these injuries typically is based on the characteristics of $\mathrm{C} 2$ fracture. The management options include traction followed by immobilization, semirigid immobilization with cervical collar, rigid immobilization with halo, Minerva, sterno-occipito-mandibular immobilizer, posterior C1-2 fusion and anterior odontoid screw fixation [33]. Longo et al. [34] in a systematic review on halo immobilization, concluded that halo immobilization is a safe and effective treatment modality in combination injuries.

Conservative management with external immobilization (cervical collar or cervical traction with halo immobilization) is 
sufficient in most cases (approximate healing in 12 weeks) [35] The two most controversial situations include C1-type 2 odontoid and C1-Hangman fracture combinations. Immobilization with halo or surgical fusion should be considered in unstable C1-type 2 odontoid fractures, which may be defined as atlanto-dens interval of $5 \mathrm{~mm}$ or more [36]. Similarly, rigid halo immobilization or surgical fusion needs to be considered in unstable C1-Hangmen fracture combinations with $\mathrm{C} 2-3$ angulation of $11^{\circ}$ or more $[37,38]$.

\section{References}

1. Jefferson G (1920) Fractures of the atlas vertebra: report of four cases and a review of those previously reported. Br J Surg 7(27): 407-422.

2. Spence KF, Decker S, Sell KW (1970) Bursting atlantal fracture associated with rupture of the transverse ligament. J Bone Joint Surg Am 52(3): 543-549.

3. Dickman CA, Greene KA, Sonntag VK (1996) Injuries involving the transverse atlantal ligament: classification and treatment guidelines based upon experience with 39 injuries. Neurosurgery 38(1): 44-50.

4. Heller JG, Viroslav S, Hudson (1993) Jefferson fractures: the role of magnification artifact in assessing transverse ligament integrity. J Spinal Disord 6(5): 392-396.

5. Hadley MN, Dickman CA, Browner CM, Sonntag VK (1988) Acute traumatic atlas fractures: management and long term outcome. Neurosurgery 23(1): 31-35.

6. Ryken TC, Aarabi B, Dhall SS, Gelb DE, Hurlbert RJ, et al. (2013) Management of Isolated fractures of atlas in Adults. Neurosurgery 72(3): 127-131.

7. Fowler JL, Sandhu A, Fraser RD (1990) A review of fractures of the atlas vertebra. J Spinal Disord 3(1):19-24.

8. Levine AM, Edwards CC (1991) Fractures of the atlas. J Bone Joint Surg Am 73(5): 680-691.

9. Landells CD, Van Peteghem PK (1988) Fractures of the atlas: classification, treatment and morbidity. Spine (Phila Pa 1976) 13(5): 450-452.

10. Horn EM, Theodore N, Feiz-Erfan I, Lekovic GP, Dickman CA, et al. (2006) Complications of halo fixation in the elderly. J Neurosurg Spine 5(1): 4649.

11. Lee TT, Green BA, Petrin DR (1998) Treatment of stable burst fracture of the atlas (Jefferson fracture) with rigid cervical collar. Spine (Phila Pa 1976) 23(18): 1963-1967.

12. Anderson LD, D’Alonzo RT (1974) Fractures of the odontoid process of the axis. J Bone Joint Surg Am 56(8): 1663-1674.

13. Grauer JN, Shafi B, Hilibrand AS, Harrop JS, Kwon BK,et al. (2005) Proposal of a modified, treatment oriented classification of odontoid fractures. Spine J 5(2): 123-129.

14. Greene KA, Dickman CA, Marciano FF, Drabier JB, Hadley MN, et al. (1997) Acute axis fractures: analysis of management and outcome in 340 consecutive cases. Spine (Phila Pa 1976) 22(16): 1843-1852.

15. Platzer P, Thalhammer G, Ostermann R, Wieland T, Vécsei V, et al. (2007) Anterior screw fixation of odontoid fractures comparing younger and elderly patients. Spine (Phila Pa 1976) 32(16): 1714-1720.

16. Ryken TC, Hadley MN, Aarabi B, Dhall SS, Gelb DE, et al. (2013) Management of Isolated Fractures of the Axis in Adults. Neurosurgery 72: 132-150.

17. Nourbakhsh A, Shi R, Vannemreddy P, Nanda A (2009) Operative versus nonoperative management of acute odontoid type II fractures: a metaanalysis. J Neurosurg Spine 11(6):651-658.
18. Frangen TM, Zilkens C, Muhr G, Schinkel C (2007) Odontoid fractures in the elderly: dorsal C1/C2 fusion is superior to halo-vest immobilization. J Trauma 63(1): 83-89.

19. Effendi B, Roy D, Cornish B, Dussault RG, Laurin CA (1981) Fractures of the ring of the axis: a classification based on the analysis of 131 cases. J Bone Joint Surg Br 63-B(3): 319-327.

20. Levine AM, Edwards CC (1985) The management of traumatic spondylolisthesis of the axis. J Bone Joint Surg Am 67(2): 217-226.

21. Li XF, Dai LY, Lu H, Chen XD (2006) A systematic review of the management of Hangman's fractures. Eur Spine J 15(3): 257-269.

22. Xu H, Zhao J, Yuan J, Wang C (2010) Anterior discectomy and fusion with internal fixation for unstable Hangman's fracture. Int Orthop 34(1): 8588.

23. ElMiligui Y, Koptan W, Emran I (2010) Transpedicular screw fixation for type II Hangman's fracture: a motion preserving procedure. Eur Spine J 19(8): 1299-1305.

24. Benzel EC, Hart BL, Ball PA, Baldwin NG, Orrison WW, et al. (1994) Fractures of the C-2 vertebral body. J Neurosurg 81(2): 206-212.

25. German JW, Hart BL, Benzel EC (2005) Nonoperative management of vertical C2 body fractures. Neurosurgery 56(3): 516-521.

26. Ding T, Maltenfort M, Yang H (2010) Correlation of C2 fractures and vertebral artery injury. Spine (Phila Pa 1976) 35(12): E520-E524.

27. Korres DS, Papagelopoulos PJ, Mavrogenis AF, Sapkas GS, Patsinevelos A, et al. (2004) Multiple fractures of the axis. Orthopedics 27(10):10961099.

28. (2002) Management of combination fractures of the atlas and axis in adults. In: Guidelines for the management of acute cervical spine and spinal cord injuries. Neurosurgery 50(3 suppl): S140-S147.

29. Jefferson G (1920) Fractures of the atlas vertebra: report of four cases and a review of those previously reported. Br J Surg 7: 407-422.

30. Ryken TC, Hadley MN, Aarabi B, Dhall SS, Gelb DE, et al. (2013) Management of acute combination fractures of atlas and axis in Adults. Neurosurgery 72: 151-158.

31. Fujimura Y, Nishi Y, Chiba K, Kobayashi K (1995) Prognosis of neurological deficits associated with upper cervical spine injuries. Paraplegia 33(4): 195-202.

32. Levine AM, Edwards CC (1986) Treatment of injuries in the C1-C2 complex. Orthop Clin North Am 17(1): 31-44.

33. Agrillo U, Mastronardi L (2006) Acute combination fracture of atlas and axis: "triple" anterior screw fixation in a 92-year-old man: technical note. Surg Neurol 65(1): 58-62.

34. Longo UG, Denaro L, Campi S, Maffulli N, Denaro V (2010) Upper cervical spine injuries: indications and limits of the conservative management in Halo vest: a systematic review of efficacy and safety. Injury 41(11):11271135.

35. Daentzer D, Flörkemeier T (2009) Conservative treatment of upper cervical spine injuries with the halo vest: an appropriate option for all patients independent of their age? J Neurosurg Spine 10(6): 543-550.

36. Lee TT, Green BA, Petrin DR (1998) Treatment of stable burst fracture of the atlas (Jefferson fracture) with rigid cervical collar. Spine (Phila Pa 1976) 23(18): 1963-1967.

37. Fielding JW, Francis WR, Hawkins RJ, Pepin J, Hensinger R (1989) Traumatic spondylolisthesis of the axis. Clin Orthop Relat Res 239: 4752.

38. Agrillo U, Mastronardi L (2006) Acute combination fracture of atlas and axis: "triple" anterior screw fixation in a 92-year-old man: technical note. Surg Neurol 65(1): 58-62. 